\title{
Two phase heat transfer and flow regimes of R-134a and R-410A during condensation in horizontal micro-fin tubes
}

\author{
Rajeev Kukreja ${ }^{1 *}$, Sanjeev Jain², Radhey Sham Aggarwal ${ }^{3}$ \\ ${ }^{1}$ Department of Mechanical Engineering, National Institute of Technology, Jalandhar 144008, Inida \\ ${ }^{2}$ Department of Mechanical Engineering, Indian Institute of Technology, Delhi 110016, India \\ ${ }^{3}$ Senior Advisor and Coordinator for HCFC Phase-out, Project "Montreal Protocol" Ozone Cell, India Habitat Centre, Lodhi \\ Road, New Delhi 110 003, India
}

Corresponding Author Email: kukrejar@nitj.ac.in

https://doi.org/10.18280/ijht.360440

Received: 9 February 2018

Accepted: 6 November 2018

\section{Keywords: \\ micro fin tubes, flow regimes, condensation heat transfer, pressure drop, helix angle}

\begin{abstract}
Micro fin tubes are widely being used in condensers and evaporators of commercial air conditioners. These tubes enhance the heat transfer without causing the similar increase in refrigerant charge and pressure drop. The condensation heat transfer characteristics are strongly dependent on prevailing flow regimes. The flow regimes, further, depend on the mass flux, vapour quality and fluid properties. Conventionally, two phase heat transfer correlations are used for the design of condenser [1-2] etc. These correlations can pose serious errors, if these are inconsistent with the prevailing flow regime [3]. The present study deals with the experimental investigations on local condensation heat transfer coefficient and local flow regimes at saturation temperatures of $35^{\circ} \mathrm{C}$ and $40^{\circ} \mathrm{C}$ respectively, in mass flux range of 200-400 kg/m $\mathrm{m}^{2} \mathrm{~s} \&$ vapour quality range of $0.1-0.9$ for $\mathrm{R} 134 \mathrm{a}$ and $\mathrm{R} 410 \mathrm{~A}$ respectively using two horizontal micro fin tubes having helix angles of $15^{\circ}$ and $18^{\circ}$ respectively. Various flow regimes encountered during the condensation of refrigerants R134a have been captured with high speed digital CMOS camera. Analysis of these flow regimes has been carried out to understand the relationship between the heat transfer coefficient and the prevailing flow regimes. Most of the flow regimes are observed to lie in Annular, Semi annular and Stratified zone. Three existing flow regime maps, namely that of Berbera et al. [4], Tandon et al. [5] and Thome et al. [6] have been used to predict the flow regimes corresponding to different experimental conditions. The observed flow regimes are then compared with the predicted flow regimes to check the applicability of existing flow regime maps. It has been observed that the prediction capability of Tandon et al. [5] flow regime map is very good as compared to Breber et al. [4] and Thome et al. [6] flow regime maps, for both pure refrigerant (R134a) and mixture refrigerant R410A. The local heat transfer coefficients for R134a \& R410A ranged from $1095-8797 \mathrm{~W} / \mathrm{m}^{2}-\mathrm{K}$ \& 1390 $7255 \mathrm{~W} / \mathrm{m}^{2}-\mathrm{K}$ respectively. The uncertainties in the measurement of refrigerant mass flow rate, test condenser water flow rate, refrigerant saturation temperature, wall temperature and water temperatures are $\pm 0.002 \mathrm{~kg} / \mathrm{s}, \pm 0.05 \mathrm{lpm}, \pm 0.15^{\circ} \mathrm{C}, \pm 0.5^{\circ} \mathrm{C} \& \pm 0.1^{\circ} \mathrm{C}$ respectively. The overall uncertainty in the measurement of local heat transfer coefficient was in the range of $\pm 6-40 \%$
\end{abstract}

\section{INTRODUCTION}

Performance characteristics, such as heat transfer coefficient and pressure drop, of condensers used in refrigeration and air conditioning, power and chemical industries are strongly dependent on two phase flow regimes prevailing during the condensation process. These flow regimes depend on the mass flux, vapour quality, fluid properties and tube dimensions. The flow regimes provide a mechanism for transport of heat, and influence the pressure drop in condensers due to the different interactions between the vapour and liquid phases and their tube wall interactions. It is very important to know; what flow pattern is expected to exist at certain flow conditions inside a condenser. During condensation in horizontal micro fin tubes, the existence of a specific flow regime is governed by the dominance of either the vapour shear force or the gravity force. While the dominance of shear forces leads to a dispersed / annular flow at high mass fluxes and high vapour qualities, on the hand, the dominance of gravity forces leads to a divided flow or stratified flow. The intermittent flow normally occurs at low mass flux and high liquid inventory. In the present study, a flow regime based analysis has been conducted to understand the local heat transfer coefficients and pressure drop. The various flow regimes encountered during the condensation at different mass fluxes and vapour qualities are captured with the help of high speed digital camera. Most of the data obtained falls into Annular, Semi Annular \& Wavy flow regime. The flow patterns observed during the experimental study are plotted on three existing flow regime maps, namely, Breber et al. [4] flow regime map, Tandon et al. [5] flow regime map and Thome et al. [6] flow regime map. It is observed that qualitatively, there is no difference between the flow regimes obtained during condensation in horizontal 
smooth tubes with the flow regimes obtained in the horizontal micro finned tubes.

\section{EXPERIMENTAL TEST RIG}

An experimental test facility as shown in Figure 1 was set up for studying the condensation characteristics of R134a and R410A in horizontal micro-fin tubes. The experimental facility consisted of three closed piping loops: one was the refrigerant loop \& the other two were coolant water loops. The refrigerant condenser comprised of three sections viz., precondenser, test-condenser and after-condenser. The testcondenser was a horizontal tube in tube heat exchanger of $3 \mathrm{~m}$ length with refrigerant flowing inside micro fin copper tube of
8.54/8.46 mm ID and 9.54/9.52 mm OD. The coolant water flew in the counter flow direction in the outer annulus. The pre-condenser was used to vary the vapour quality at inlet to test condenser by varying the flow rate and/or cooling water temperature. The pre-condenser was a tube in tube counter flow heat exchanger with the refrigerant flowing inside copper tube and water flowing through the annulus. The precondenser tube was bent in a six row arrangement. The superheated refrigerant vapours were condensed to the desired experimental conditions; the pre- condenser was installed before the test condenser. An after-condenser was installed downstream of the test condenser for achieving the complete condensation of partially condensed refrigerant from the testcondenser.

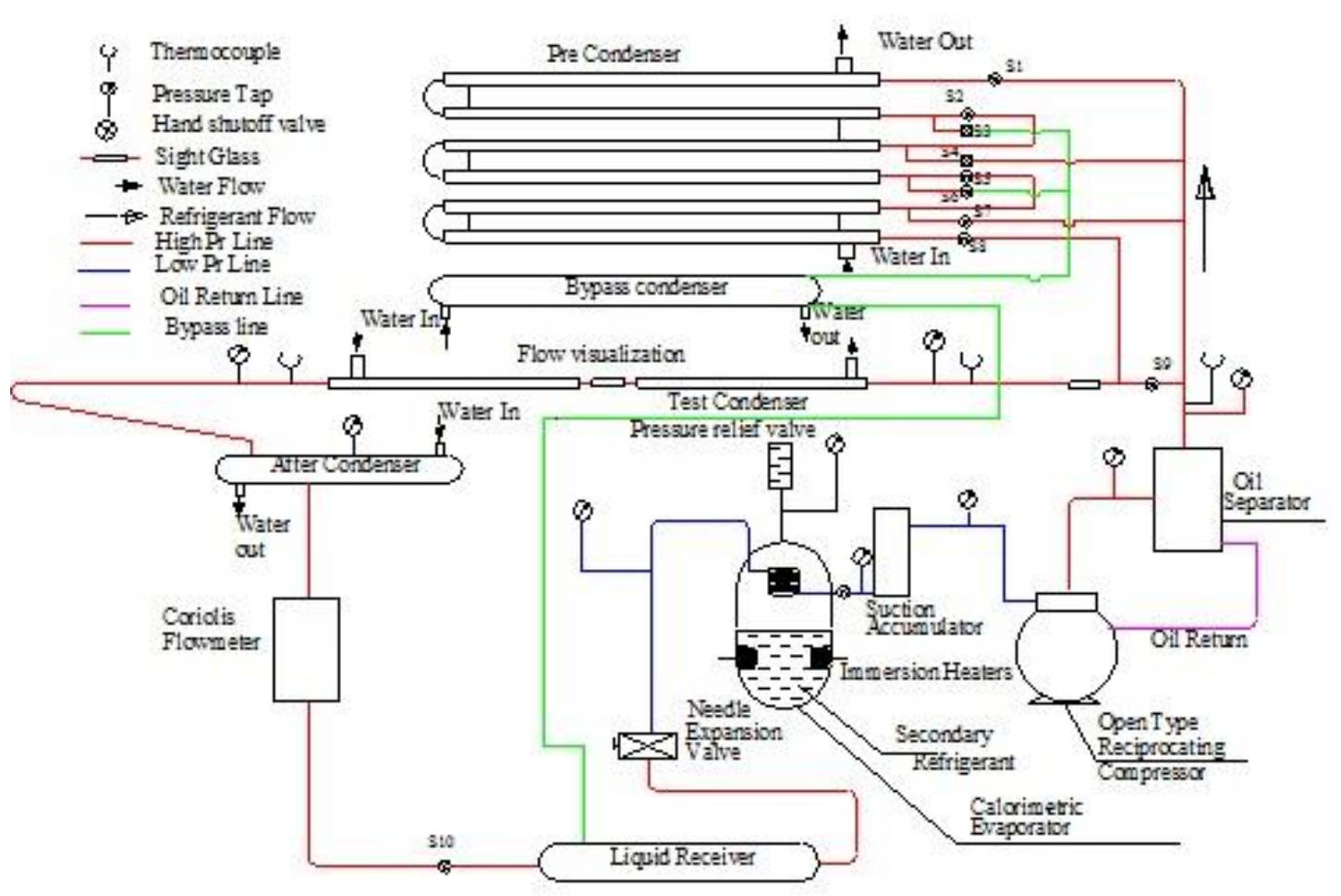

Figure 1. Schematic sketch of Experimental Test facility

The cooling water required for condensing the refrigerant vapours in the pre-condenser, test-condenser and aftercondenser was supplied at constant temperature from two water tanks. A three-ton capacity, twin cylinder, reciprocating compressor circulated the refrigerant through the system. The temperatures on the outer surface of the test section in the test condenser, the refrigerant temperatures at the inlet and exit of test section were measured using $\mathrm{T}$ type (Copper-Constantan) thermocouples. Pt-100 RTDs were used for cooling water temperature measurements in pre, test and after-condensers. An electronic Coriolis flow meter installed between the after-condenser and liquid receiver measured the mass flow rate of the circulating refrigerant. Refrigerant and coolant water temperatures were measured at the inlet and exit of test-condenser. The refrigerant pressures were measured by pressure transducers while the difference between the test-condenser inlet and exit pressure was measured with the help of a differential pressure transmitter. A data acquisition switching unit of Agilent make, with three Armature Multiplexer cards was coupled to computer record the experimental data. The measurement errors were estimated by the method suggested by Kline and McClintock [7]. Thermophysical and transport properties of the refrigerants used in this study were calculated by REFPROP 7 [8].

\section{DATA REDUCTION}

\subsection{Deduction of inlet and outlet vapour quality}

The vapour quality at the inlet to the test section was calculated by carrying the enthalpy balance of pre-condenser as per following equations:

$$
\begin{aligned}
& Q_{P c}=\dot{\mathrm{m}}_{w, P c} c_{P}\left(T_{P c, w, o}-T_{P c, w, i}\right) \\
& Q_{P c}=\dot{\mathrm{m}}_{r}\left(i_{r, P c, i}-i_{r, P c, o}\right) \\
& i_{r, P c, o}=i_{f}+x_{i} i_{f g}
\end{aligned}
$$


$x_{i}=\frac{1}{i_{f g}}\left[\left(i_{P c, i}-i_{g}\right)-\frac{Q_{P c}}{m_{r}}\right]$

$Q_{t c}=\dot{\mathrm{m}}_{w, t c} C_{p}\left(T_{t c, w, o}-T_{t c, w, i}\right)$

$Q_{t c}=\dot{\mathrm{m}}_{r}\left(i_{r, t c, i}-i_{r, t c, o}\right)$

$i_{r, t c, o}=i_{f}+x_{o} i_{f g}$

\subsection{Deduction of local condensation heat transfer coefficient}

The local heat transfer coefficient was calculated as per following equation:

$h=\frac{Q_{t c} / A}{T_{r}-T_{\text {wall,i }}}$

$T_{\text {wall }, i}=T_{w a l l, o}+Q_{t c} \times^{\ln \left(\frac{D_{o}}{D_{i}}\right)} / 2 \pi k l$

\section{FLOW REGIMES}

The experiments are conducted to study the condensation characteristics of refrigerant R134a and R410A by varying the mass flux, vapour quality and saturation condensation temperature in $15^{\circ}$ and $18^{\circ}$ helix horizontal micro fin tubes. During each test run, flow is visualized through glass tube test section with the help of high speed digital camera. Flow visualization requires specific description and characteristics of flow regimes on the basis of which these are identified. The description and characteristics on the basis of which flow regimes are identified. In addition, the experimental data points are plotted on the existing flow regime maps proposed by Breber et al. [4], Tandon et al. [5] and Thome et al. [6].

\subsection{Observed flow regimes of R134a}

Figure 2 illustrates the captured images in black and white format for R134a in the mass flux ranges of $200-400 \mathrm{~kg} / \mathrm{m}^{2}-\mathrm{s}$ at the different values of the vapour qualities.
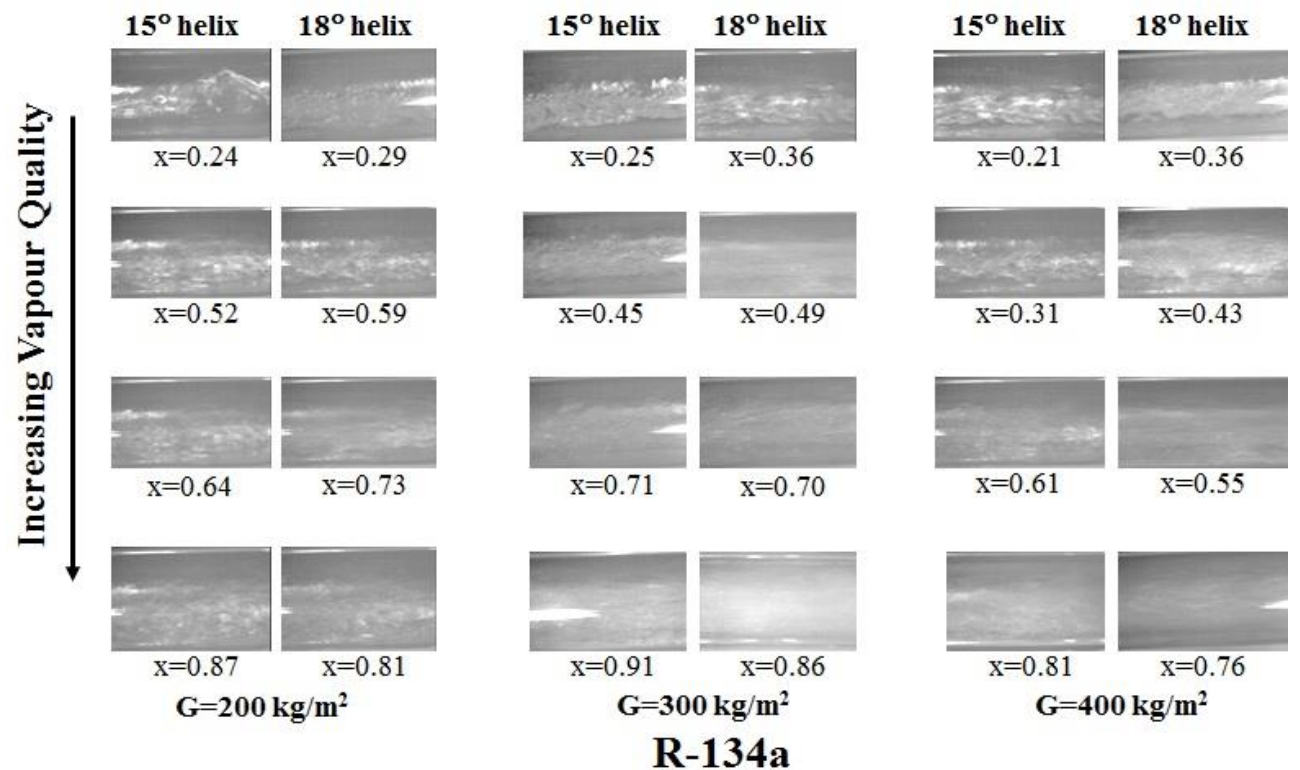

Figure 2. Flow observations obtained during condensation of R134a at different mass fluxes in $15^{\circ}$ and $18^{\circ}$ helix micro fin tubes

It can be seen from the above observed flow regimes that three types of flow regimes are mainly captured in the present study. These are wavy, semi annular and annular. On close examination of the captured flow regimes, it is observed that the flow regime changes from wavy flow regime to semi annular/annular with the increase in vapour quality. For the observations pertaining to lower mass flux of $200 \mathrm{~kg} / \mathrm{m}^{2}-\mathrm{s}$, the transition from wavy to semi annular/annular occurs at higher vapour qualities up to $0.4-0.5$. The flow essentially remains wavy up to vapour qualities of 0.4-0.5 and thus lower values of heat transfer coefficients are obtained. However, for R134a, the threshold vapour quality for the transition of flow regime from wavy to annular decreases as the helix angle is increased from 15 to $18^{0}$ due to better redistribution of the refrigerant around the circumference of the micro fin tube. This effect remains insignificant at lower mass flux as the remains gravity controlled but at higher mass flux as can be seen in flow observations the transition from wavy starts at vapour qualities near or greater than 0.2 which is much below 0.5 as observed in mass flux range of $200 \mathrm{~kg} / \mathrm{m}^{2}-\mathrm{s}$. The effect of increased helix angle is also visible at higher mass fluxes as compared to lower mass flux. The range of semi annular /annular flow regime varies from 0.45-0.9 for flows with lower mass fluxes to 0.3-0.9 for flows with mass flux of $300-400 \mathrm{~kg} / \mathrm{m}^{2}-\mathrm{s}$.

4.1.1 Comparison of predicted and observed flow regimes with Breber et al. map

The experimental data related to R134a are plotted using EES on flow regime maps proposed by Breber et al. [4], Tandon et al. [5] and Thome et al. [6]. These flow regime maps are compared with the flow regimes recorded with the high speed digital camera illustrated in Figures (3)-(5). The respective Figure with caption "a" and Caption " $b$ " are for $15^{\circ}$ and $18^{\circ}$ helix angle. 


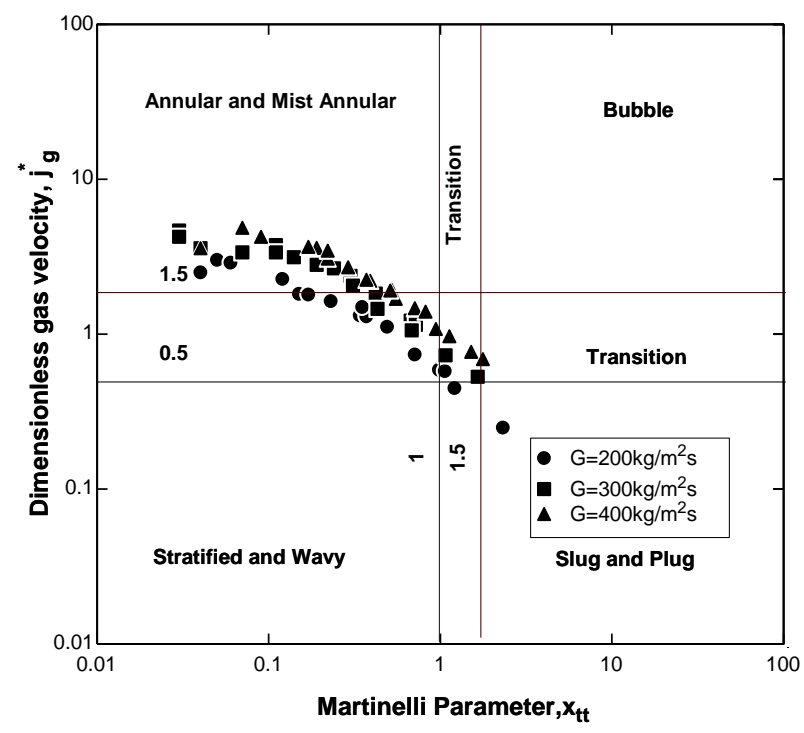

(a) $15^{\circ}$ helix

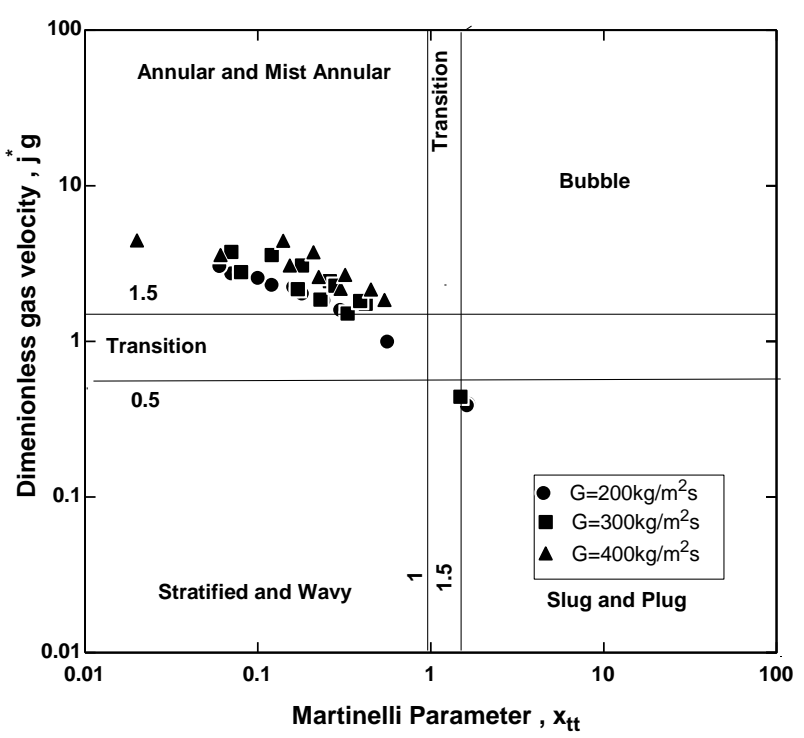

(b) $18^{\circ}$ helix

Figure 3. (a) and (b) Experimental data plotted on Breber et al. [4] flow regime map for $\mathrm{R} 134 \mathrm{a}$ in $15^{\circ}$ and $18^{\circ}$ helix micro fin tube

It is found that there is a considerable discrepancy between the observed and predicted flow regimes. Of the all the 93 experimental data points plotted, only $58 \%$ could correctly predict the observed flow regimes. Breber et al. [4] flow regime map fails to predict the flow regimes at lower and middle vapour qualities in the mass flux of $200 \mathrm{~kg} / \mathrm{m}^{2}-\mathrm{s}$ and in the lower vapour qualities (up to $\mathrm{x}=0.3-0.4$ ) for mass fluxes in the range of $300-400 \mathrm{~kg} / \mathrm{m}^{2}$-s. The Breber et al. [1] flow regime map predicted these points in the transition region between annular/mist and wavy stratified flows but the same are in the wavy region as per the observed flow regimes shown in Figure 3(a) and Figure 3(b).

4.1.2 Comparison of predicted and observed flow regimes with Tandon et al. [5] map

In contrast to Breber et al. [4] flow regime map, Tandon et al. [5] correctly predicts most of the flow regimes in the lower mass flux range, which are essentially wavy as per the observed flow regimes. On close examination, it is observed that about $71 \%$ of the experimental data plotted on this map correctly predicts the actual flow regimes as shown in Figure 4(a) and Figure 4(b).

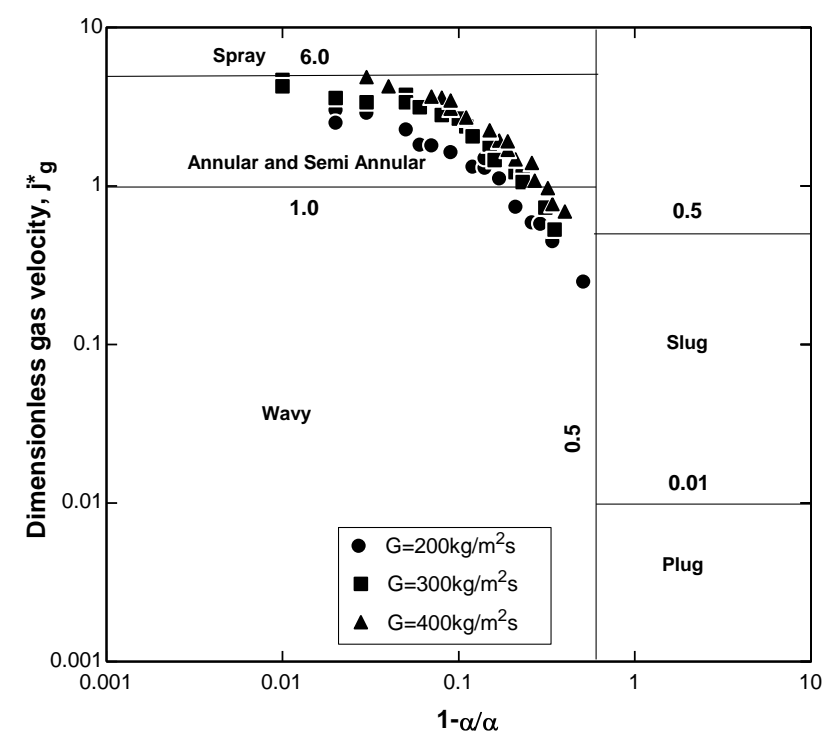

(a) $15^{\circ}$ helix

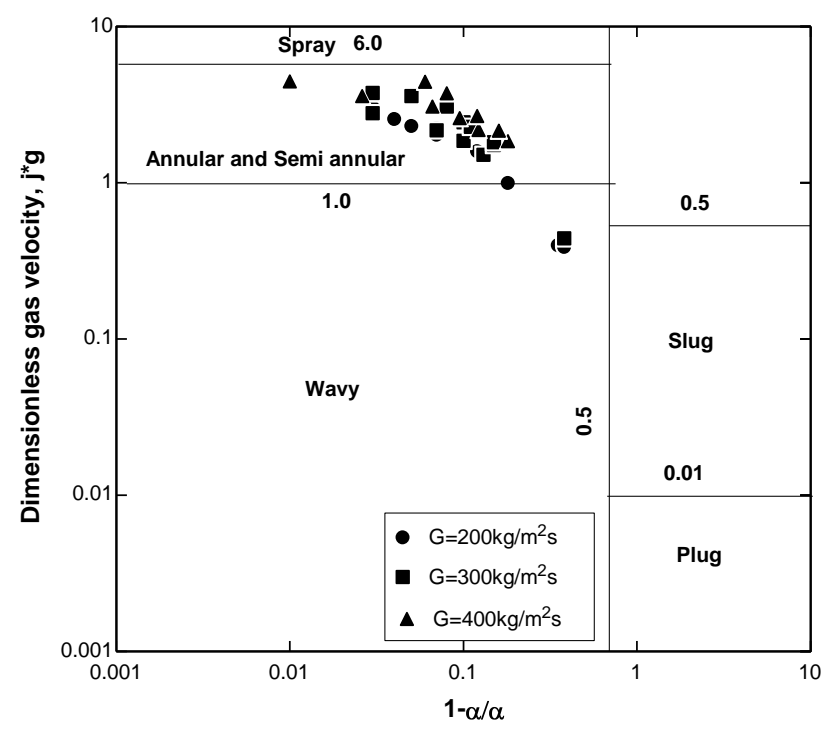

(b) $18^{\circ}$ helix

Figure 4. (a) and (b) Experimental data plotted on Tandon et al. [5] flow regime map for R134a in $15^{\circ}$ and $18^{\circ}$ helix micro fin tube

4.1.3 Comparison of predicted and observed flow regimes with Thome et al. [6] map

As described earlier, experimental data for R134a in the present study are primarily in the intermittent and annular flow regimes, with few data in stratified wavy flow as shown in Figure 5(a) and Figure 5(b). The discrepancy between the predicted and recorded flow regimes for this map is at higher mass fluxes where the flow regime maps predict the intermittent while the actual flow regimes seem to be in semi annular. It is worth mentioning here that the definitions of the intermittent and Annular flow regimes are not clearly stated in this map. Moreover, the authors have developed the same heat transfer correlation for the intermittent, annular and mist flows. It is observed that about $62 \%$ of the experimental data plotted on this map correctly predicts the observed flow regimes. 


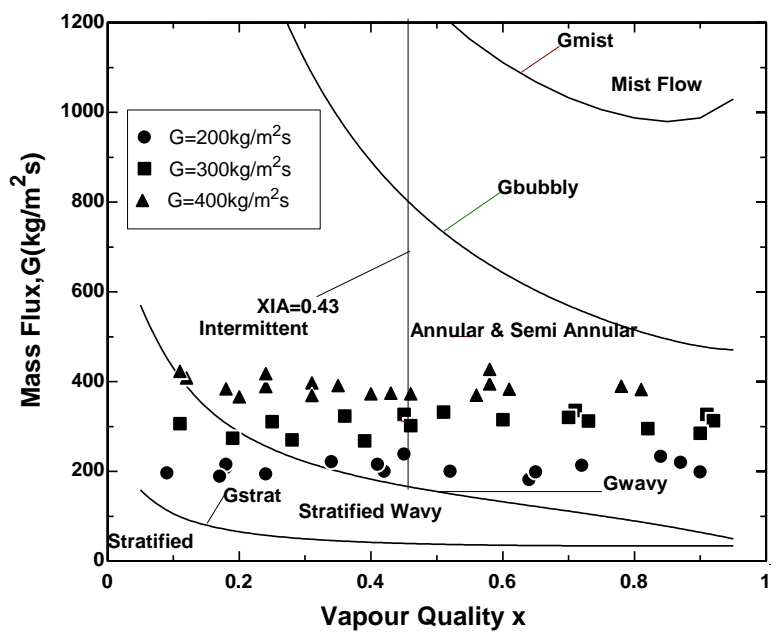

(a) $15^{\circ}$ helix

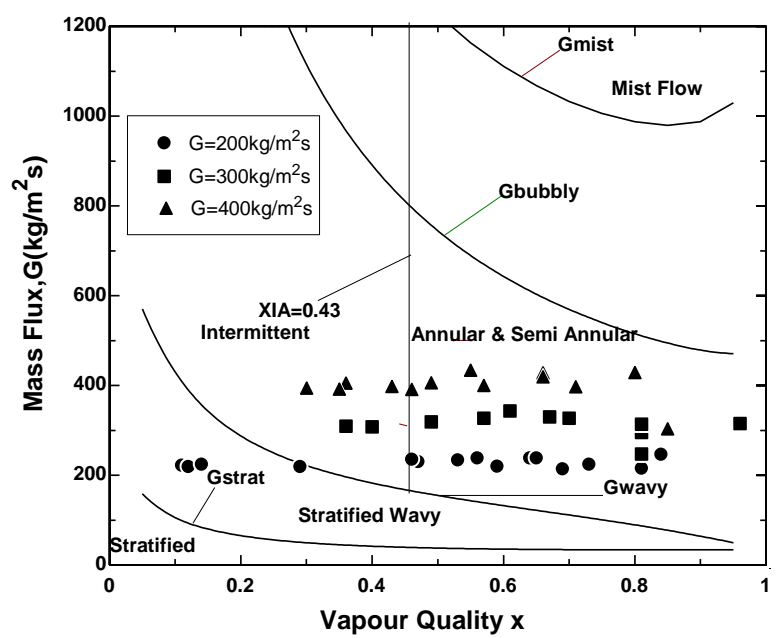

(b) $18^{\circ}$ helix

Figure 5. (b) Experimental data plotted on Thome et al. [6] flow regime map for $\mathrm{R} 134 \mathrm{a}$ in $18^{\circ}$ helix micro fin

\subsection{Observed flow regimes of $R-410 \mathrm{~A}$}

Figure 6 illustrates the captured images for R410A at the mass flux ranges of $200-300 \mathrm{~kg} / \mathrm{m}^{2}$-s at the different values of the vapour qualities. Similar trends have been observed for refrigerant R410A as that of R134a.Here also predominantly, three flow regimes are seen namely, wavy, semi annular and annular.

4.2.1 Comparison of predicted and observed flow regimes with Breber et al. [4], Tandon et al. [5] and Thome et al. [6] map

The experimental data consists of 23 data points for $15^{0}$ helix micro tube and 32 data points obtained for $18^{0}$ helix micro fin tube (as shown in Figures (7)-(9)) at saturation temperatures of $30 \& 35^{\circ} \mathrm{C}$. Similar trends as in $\mathrm{R} 134 \mathrm{a}$ are observed, as a majority of the experimental data for R410A from the present study fall in the annular and mist regions and a very few points in the transition and slug\& plug flow regimes. It can also be observed that even though none of the data fall in the stratified-wavy regions, many of the data points lie in the transition region between annular/mist and wavy stratified flows.

\section{INFLUENCE OF FLOW REGIMES ON CONDENSATION HEAT TRANSFER}

The flow regimes prevailing during condensation of refrigerants in micro fin tubes influence the condensation heat transfer. This can be seen from the observed flow regimes captured with the high speed digital camera. At the highest vapour qualities $(0.75<\mathrm{x}<0.90)$ and at high mass fluxes in the range of $250-400 \mathrm{~kg} / \mathrm{m}^{2}-\mathrm{s}$, the prevailing flow regime is annular wherein the liquid film surrounding the vapour core is stable and thin. The refrigerant flow moves forward with a twisting or swirling motion due to the helix of micro fin tube. The micro fins present near the liquid-vapour interface cause further turbulence. The local condensation heat transfer coefficients obtained during this type of flow regime are maximum.

As the condensation proceeds further, condensed liquid starts accumulating at the bottom of the horizontal condenser tube. However, the presence of micro fins ensures that some of the liquid settling at the bottom portion
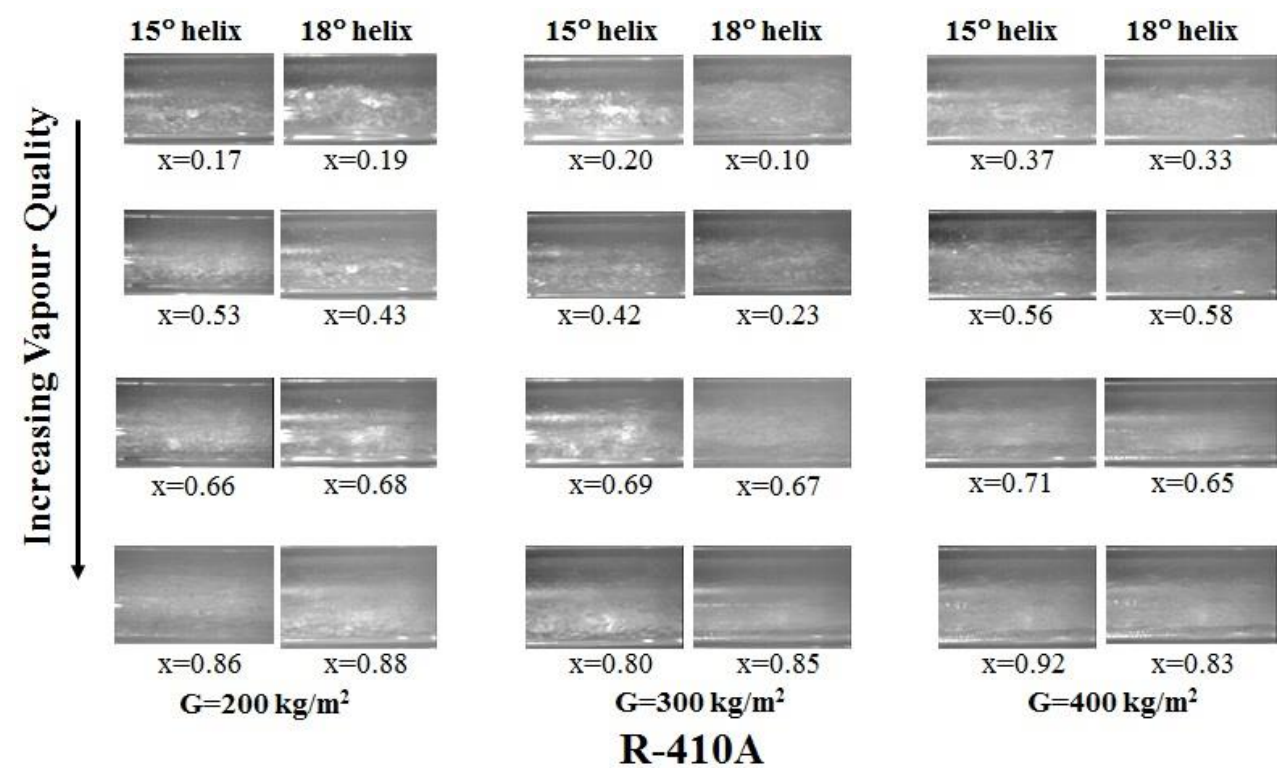

Figure 6. Flow observations obtained during condensation of R410A at different mass fluxes in $15^{\circ}$ and $18^{\circ}$ helix micro fin tubes 


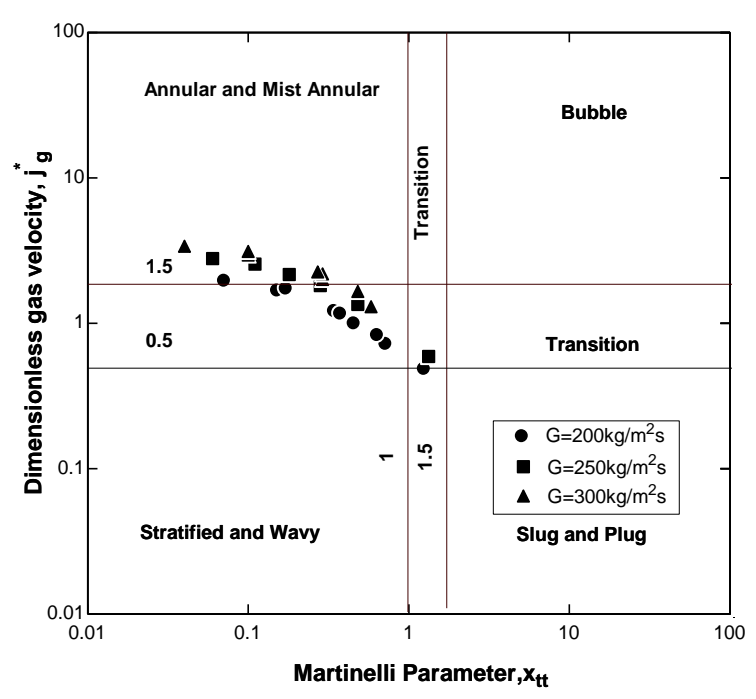

(a) $15^{\circ}$ helix

(b)

Figure 7. (a) Experimental data plotted on Breber et al. [4] flow regime map for $\mathrm{R}-410 \mathrm{~A}$ in $15^{\circ}$ helix micro fin tube

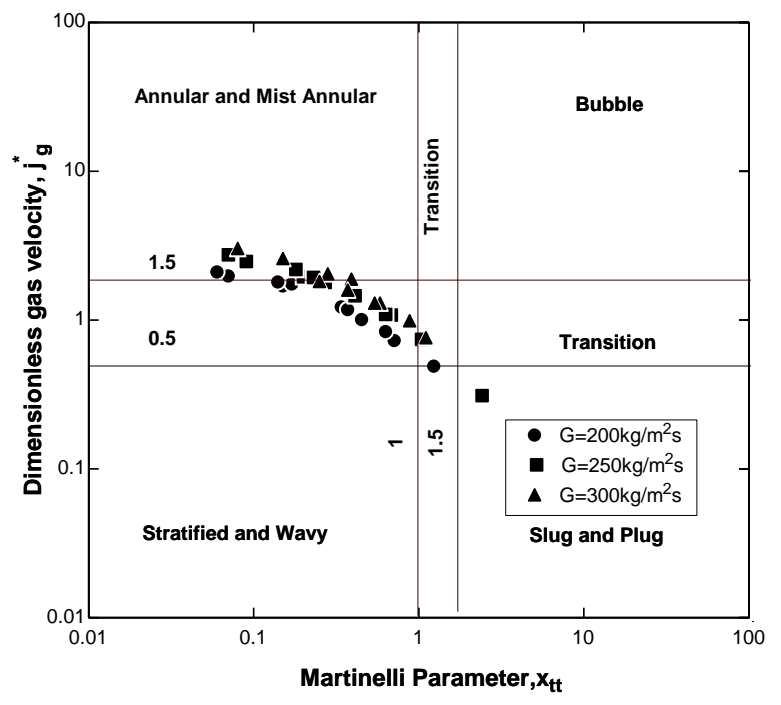

(b) $18^{\circ}$ helix

Figure 7. (b) Experimental data plotted on Breber et al. [4] flow regime map for R-410A in $15^{\circ}$ helix micro fin tube

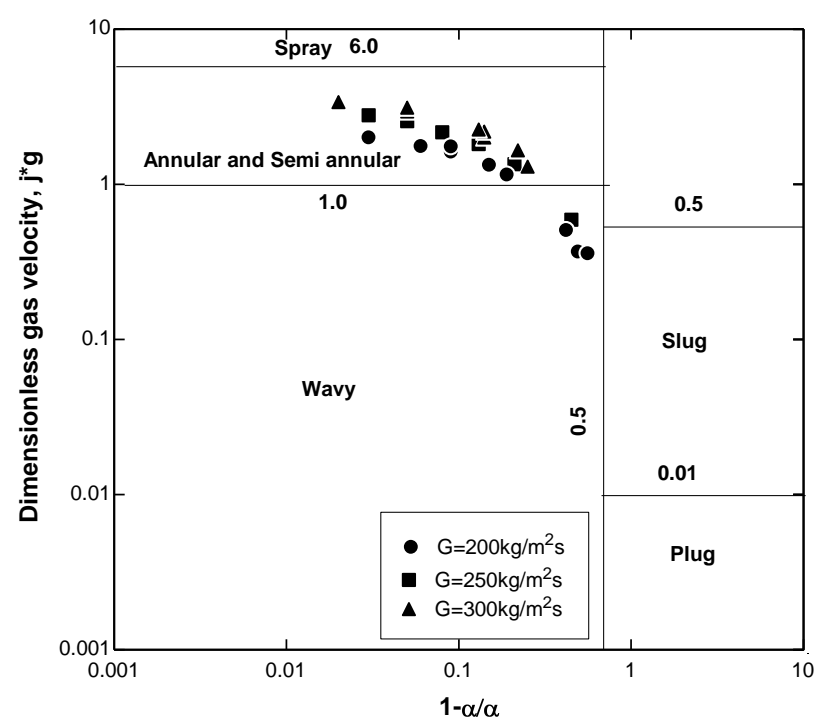

(a) $15^{\circ}$ helix

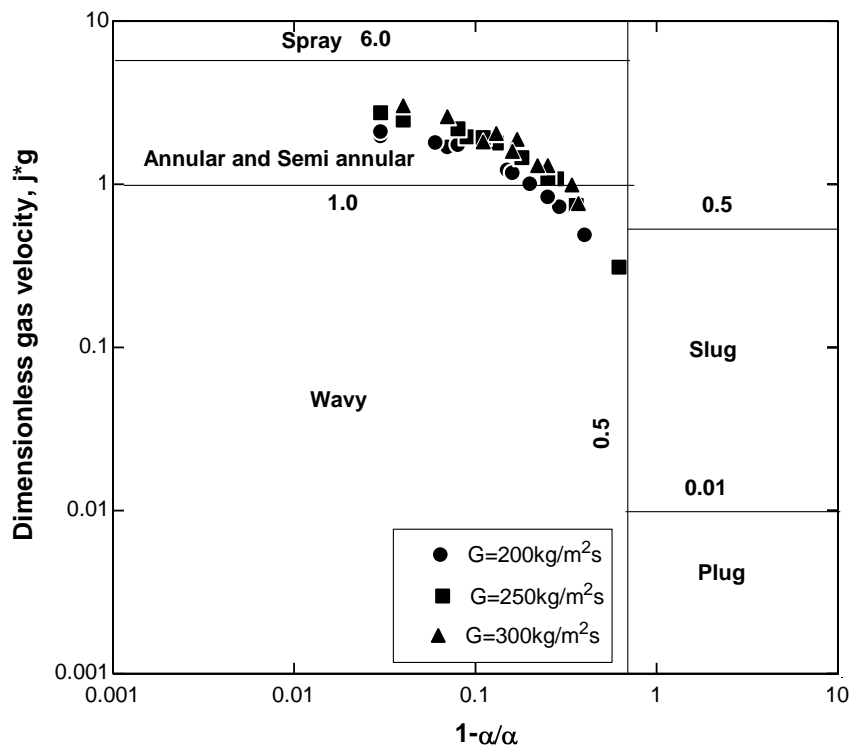

(b) $18^{\circ}$ helix

Figure 8. (a) and (b) Experimental data plotted on Tandon et al. [5] flow regime map for R-410A in $15^{\circ}$ and $18^{\circ}$ helix micro fin tube

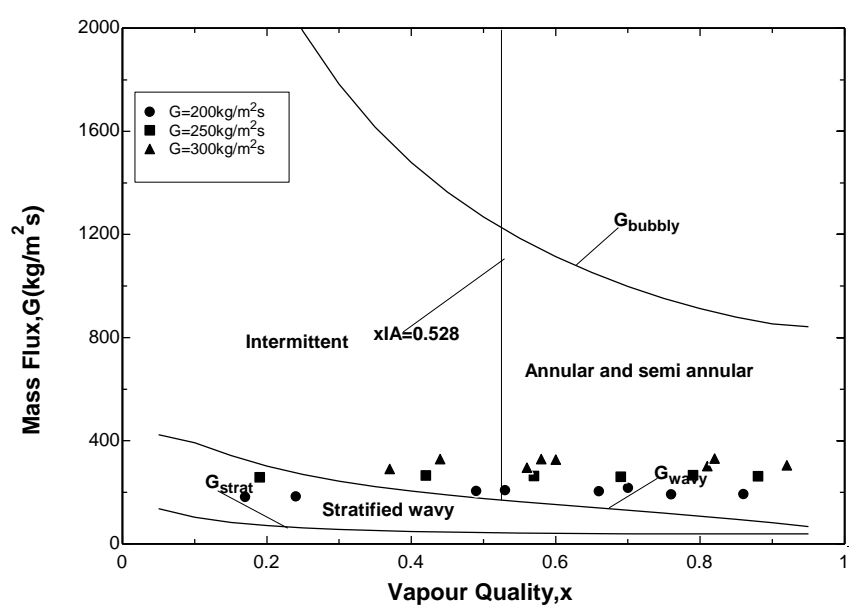

(a) $15^{\circ}$ helix

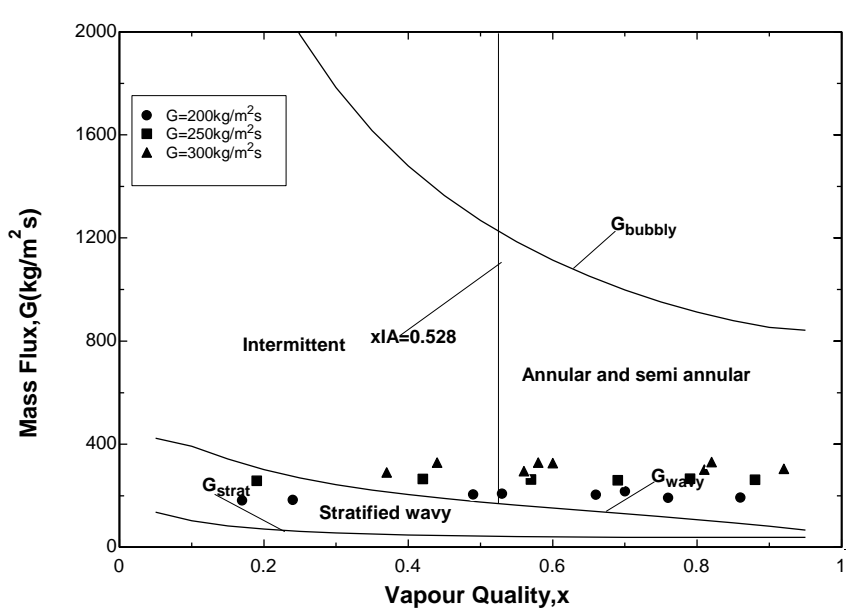

(b) $18^{\circ}$ helix

Figure 9. (a) and (b) Experimental data plotted on Thome et al. [6] flow regime map for R-410A in $15^{\circ}$ and $18^{\circ}$ helix micro fin tube 


\section{CONCLUSIONS}

The experimental data obtained during the condensation of two refrigerants, R134a and R410A has been plotted on Breber et al. [4], Tandon et al. [5] and Thome et al. [6] to predict the various flow regimes prevailing at different mass fluxes and vapour qualities. The observed flow regimes are compared with those predicted by the three flow regime maps mentioned above. It has been observed that the prediction capability of Tandon et al. [5] flow regime map is very good as compared to Breber et al. [4] and Thome et al. [6] flow regime maps, for both pure refrigerant (R134a) and mixture refrigerantR410A. Tandon et al. [5] flow regime map predicted about $71 \%$ and $82 \%$ of the experimental data for the refrigerants, $\mathrm{R} 134 \mathrm{a}$ and $\mathrm{R} 410 \mathrm{~A}$ respectively. Thome et al. [6] flow regime map predicted about $62 \%$ and $75 \%$ of the experimental data for refrigerants, R134a and R410A.The Breber et al. [4] flow regime map predicted 58\% and 55\% of the experimental data for refrigerants, R134 and R410A respectively. The local heat transfer coefficients for R134a \& $\mathrm{R} 410 \mathrm{~A}$ ranged from $1095-8797 \mathrm{~W} / \mathrm{m}^{2}-\mathrm{K} \& 1390-7255 \mathrm{~W} / \mathrm{m}^{2}$ $\mathrm{K}$ respectively. The local heat transfer coefficient is lower at low mass flux(200-300kg. $\mathrm{m}^{2}$-s) \& low vapour qualities, when the flow regime is stratified however at higher mass flux and higher vapour qualities, higher heat transfer coefficients are achieved the flow regime changes to semi annulur/Annulur. The increase in the helix angle of the micro fin tube causes further increase in heat transfer coefficient as it further delays the onset of intermittent flow due to increased redistribution of the condensate liquid around the circumference and thus increases the range of vapour qualities over which the which annular and semi annular flow regime prevail. Flow regimes encountered in the present study seem to be independent of the refrigerants used and depended primarily on mass flux and vapour quality. However, the range over which the wavy, semi annular and annular flow regime prevail depends on the fluid properties.

\section{REFERENCES}

[1] Cavallini A, Censi G, Del Col D, Doretti L, Longo GA, Rosetto L. (2002). In-tube condensation of halogenated refrigerants. International Journal on HVAC \& R Research 146-161.

[2] Kedzierski MA, Gonclaves JM. (1999) Horizontal convective condensation of alternative refrigerants with in a micro fin tube. Enhanced Heat Transfer 6: 161-178. http://doi.org/10.1615/j.enhheattransf.1999.02.04

[3] Bell KJ, Taborek J, Fenoouo F. (1970). Interpretation of horizontal in-tube condensation heat transfer correlations with a two phase flow regime map. Chemical Engineering Progress Symposium. Series, 102: 150-163.

[4] Breber G, Palen JW, Taborek J. (1980). Prediction of horizontal tube side condensation of pure components using flow regime criteria. J. Heat Transfer 102: 471476.

http://doi.org/10.1115/1.3244325/j.heattransfer.1980.0 1.08

[5] Tandon TN, Varma HK, Gupta CP. (1982). A new flow regime map for condensation inside horizontal tubes. J. Heat Transfer 104: 763-768. http://doi.org/10.1115/1.3245197/j.heattransfer.1982.0 1.11

[6] Thome JR, El Hajal J, Cavallini A. (2003). Condensation in horizontal tubes, part 2: new heat transfer model based on flow regimes. Int. J. Heat Mass Transfer 46: 3365-3387. https://doi.org/10.1016/S0017-9310(03)00140-6/ int. j. heatmasstransfer.2003.08

[7] Kline SJ, McClintock FA. (1953). Describing uncertainties in single sample experiments. Experimental Thermal Fluid Science 1: 3-17. https://doi.org/10.1016/0894-1777(88)90043-X

[8] NIST. (2002). NIST standard reference database 23: NIST thermodynamic properties of refrigerants and refrigerant mixtures (REFPROP) version 7.0. National Institute of Standards and Technology (NIST), Gaithersburg, MD.

\section{NOMENCLATURE}

$\begin{array}{ll}\mathrm{A} & \begin{array}{l}\text { heat transfer surface area }\left(\mathrm{m}^{2}\right) \\ \text { specific heat capacity at constant } \\ \mathrm{C}_{\mathrm{p}}\end{array} \\ & \begin{array}{l}\text { pressure, } \\ (\mathrm{kJ} / \mathrm{kg}-\mathrm{K})\end{array} \\ \mathrm{D} & \text { tube diameter }(\mathrm{m}) \\ \mathrm{G} & \text { mass flux }\left(\mathrm{kg} / \mathrm{m}^{2}-\mathrm{s}\right) \\ \mathrm{h} & \text { heat transfer coefficient }\left(\mathrm{W} / \mathrm{m}^{2}-\mathrm{K}\right) \\ \mathrm{i} & \text { Enthalpy }(\mathrm{kJ} / \mathrm{kg}) \\ \mathrm{i}_{\mathrm{fg}} & \text { latent heat of vaporization, }(\mathrm{J} / \mathrm{kg}) \\ \mathrm{J}_{\mathrm{G}} & \text { dimensionless gas velocity, }(-) \\ \mathrm{k} & \text { thermal conductivity, }(\mathrm{W} / \mathrm{m}-\mathrm{K}) \\ \mathrm{l} & \text { length of test condenser, }(\mathrm{m}) \\ \mathrm{m} & \text { mass flow rate }(\mathrm{kg} / \mathrm{s}) \\ \mathrm{Q} & \text { heat transfer rate }(\mathrm{J} / \mathrm{s}) \\ \mathrm{T} & \text { temperature }(\mathrm{k}) \\ \mathrm{X} & \text { vapor quality }\end{array}$

\section{Subscripts}

$\begin{array}{ll}\mathrm{g} & \text { gas phase } \\ \mathrm{l}, \mathrm{f} & \text { liquid phase } \\ \mathrm{w} & \text { water } \\ \mathrm{r} & \text { refrigerant } \\ \mathrm{i} & \text { inlet } \\ \mathrm{o} & \text { outlet } \\ \mathrm{Pc} & \text { Precondenser }\end{array}$

